\title{
IDENTIFIKASI POTENSI KEARIFAN LOKAL MASYARAKAT GOLEWA KABUPATEN NGADA SEBAGAI UPAYA PENGEMBANGAN DI BIDANG PENDIDIKAN
}

\author{
${ }^{1)}$ Maria Waldetrudis Lidi, ${ }^{2)}$ Ningsih, ${ }^{3)}$ Yasinta Yenita Dhiki \\ Fakultas Keguruan dan Ilmu Pendidikan,Universitas Flores \\ e-mail: waldetrudismaria1024@ gmail.com
}

\begin{abstract}
ABSTRAK
Tujuan dari penelitan ini adalah (1) mengetahui potensi kearifan lokal masyarakat Golewa yang berhubungan dengan pendidikan (2) mendeskripsikan makna kearifan lokal masyarakat Golewa yang berhubungan dengan pendidikan. Prosedur yang dilakukan dalam penelitian (1) menganalisis potensi kearifan lokal menggunakan teknik Miles and Huberman. Potensi kearifan lokal masyarakat Golewa yang ditemukan diantaranya adalah Paruwitu, Trima, Adho/Wela Koti, dan Kosubue. Kearifan-kearifan lokal tersebut dapat digunakan dalam proses belajar mengajar berdasarkan topik pembelajaran.
\end{abstract}

Kata Kunci: Kearifan lokal, Masyarakat Golewa, Pendidikan

\section{ABSTRACT}

The objective of this research are (1) to find out the potentials of Golewa community local wisdom which related to education, and (2) To describe the meaning of Golewa local wisdom which related to education. The procedures have done in this research, (1) analysing the local wisdom potentials by using Miles and Huberman technique. The potentials of Ngada community local wisdom found such as Paruwitu, Trima, Adho/Wela Koti, and Kosubue. That local wisdom able to use in teaching and learning process based on topic of learning.

Keyword: Local Wisdom, Golewa Community, Education

\section{PENDAHULUAN}

Seiring perkembangan jaman yang semakin pesat, saat ini pendidikan merupakan salah satu kebutuhan masyarakat yang juga dianggap penting. Hal ini dikarenakan melalui pendidikan seorang pelajar akan mampu mewarisi nilai-nilai kehidupan dan pengetahuan. Sesuai dengan isi UUD pasal $28 \mathrm{C}$ ayat 1 dan 2 dan pasal 31 ayat 1 dan 2, bahwa negara telah memberikan hak bagi setiap warga Negara Indonesia untuk memperoleh pendidikan agar dapat meningkatkan kualitas hidupnya.

Pendidikan juga tidak terlepas dari budaya daerah setempat. Menurut Normina (2017), pendidikan bersifat reflektif karena mentransfer nilai-nilai kebudayaan dan juga bersifat progresif selalu berubah sesuai perkembangan kebudayaan sehingga keduanya tidak dapat dipisahkan. Ditambahkan oleh Zafi (2017), pendidikan merupakan bentuk transformasi budaya yang dapat mengalami perubahan bentuk dan model sesuai kebutuhan masyarakat untuk memberikan pengetahuan dasar sebagai bekal hidup. Dalam menginternalisasi nilai-nilai budaya termuat nilai-nilai pendidikan karakter yang dapat 
diajarkan kepada peserta didik baik dalam bentuk keteladanan, kegiatan ekstrakurikuler, maupun terintegrasi dalam kegiatan pembelajaran. Menurut Diana (2012), menyatakan bahwa pendidikan berbasis kebudayaan adalah alat penting dalam rangka melestarikan nilai-nilai kearifan lokal agar masyarakat tidak tercabut dari akarnya. Pentingnya peran budaya dalam dunia pendidikan ini juga disampaikan oleh Presiden RI dalam pidatonya dalam Pawai Pesta Kesenian Bali ke-38 di Monumen Perjuangan Rakyat Bali pada tanggal 11 Juni 2016 yang mengatakan bahwa peran budaya dalam membangun bangsa sangat mendasar karena menyangkut nilai-nilai kehidupan yang melandasi sebuah tatanan kehidupan masyarakat.

Dari beberapa pendapat diatas, dapat dikatakan bahwa kebudayaan harus dipelajari, dipahami, dan dihayati karena budaya memberikan manfaat bagi keberlangsungan hidup manusia yang lebih bernilai di masa yang akan datang. Pendidikan sebagi bentuk transformasi budaya memuat informasi yang dapat membantu manusia membuat prediksi atau perkiraan bagi kehidupannya di masa depan. Berdasarkan hubungan antara kebudayaan dan pendidikan, maka kebudayaan perlu diintegrasikan dan diadopsi dalam dunia pendidikan, baik dalam model pembelajaran maupun pendidikan nilai-nilai karakter peserta didik.

Salah satu kebudayaan yang dapat diintegrasikan dan diadopsi dalam dunia pendidikan yakni kebudayaan di Kabupaten Ngada. Kabupaten Ngada memiliki berbagai kearifan lokal, antara lain bahasa, sistem pengetahuan, sistem organisasi sosial, sistem mata pencaharian dan sistem religi serta kesenian. Dari berbagai kearifan lokal yang ada ini, sebagai seorang pendidik perlu melihat dengan teliti bahwa begitu banyak hal yang dapat dijadikan pedoman bagi pendidik untuk melaksanakan proses pembelajaran di dalam kelas dan penanaman nilai-nilai karakter peserta didik. Sebo, Adayani, dan Subiyantoro (2017) dalam penelitiannya terdahulu yang mengangkat salah satu cerita rakyat masyarakat Ngada, Wae Reke, mengangkat judul Nilai Pendidikan Karakter dan Kearifan Lokal Legenda Wae Reke Masyarakat Ngada, NTT dalam Relevansinya Dengan Pembelajaran Sastra Tingkat SLTP menjadi salah satu contoh dimana salah satu kearifan lokal yakni cerita rakyat menjadi media dalam pembelajaran. Adapun nilai-nilai karakter yang terkandung di dalamnya yakni nilai disiplin, nilai rasa ingin tahu, nilai peduli lingkungan, nilai semangat kebangsaan, nulai tanggung jawab, dan nilai jujur. Selanjutnya Laksana dan Widiastika (2017) dalam penelitiannya berjudul Pengembangan Multimedia Pembelajaran Tematik Sekolah Dasar Berbasis Budaya Lokal Masyarakat Flores secara kualitatif menjelaskan efektifitas multimedia yang dikembangkan berdasarkan kebudayaan lokal masyarakat Ngada dan berdasarkan penilaian ahli dan uji coba kepada siswa, dikategorikan sangat baik.

Berdasarkan hasil penelitian terdahulu untuk itu agar menambah wawasan kita mengenai hubungan kebudayaan dan pendidikan, perlu diidentifikasi lebih jauh potensi kearifan lokal yang dimiliki oleh masyarakat Ngada yang dapat diintegrasikan, dimodifikasi dan digunakan dalam bidang pendidikan. Hal ini bertujuan agar kita juga dapat mengetahui potensi dan makna dari kearifan lokal yang dapat dijadikan pedoman pembentukan nilai-nilai karakter peserta didik dan juga digunakan dalam proses pembelajaran melalui komponen-komponen pembelajaran di kelas. 


\section{METODE}

Penelitian ini merupakan jenis penelitian deskriptif kualitatif. Jenis penelitian deskriptif adalah penelitian yang berusaha untuk menuturkan pemecahan masalah yang ada sekarang berdasarkan data-data. Penelitian dilaksanakan di Kabupaten Ngada, kecamatan Golewa, Propinsi Nusa Tenggara Timur bulan Juni sampai bulan Desember tahun 2019. Subjek dalam penelitian ini adalah narasumber, dan kearifan lokal masyarakat setempat. Nara sumber merupakan sumber data yang dimintai informasinya sesuai dengan masalah penelitian. Sampel sumber data dipilih secara purposive yakni narasumber yang memiliki kompetensi sesuai dengan kebutuhan data. Penelitian ini bertujuan untuk mengetahui potensi-potensi kearifan lokal masyarakat Ngada dalam bidang pendidikan.

Untuk mencapai tujuan tersebut diperlukan narasumber yang memenuhi parameter yang dapat mengungkapkan hal-hal di atas. Parameternya adalah sebagai berikut.

1. Berasal dan menetap di Kabupaten Ngada, Kecamatan Golewa.

2. Menguasai atau memahami adat istiadat masyarakat Ngada melalui proses enkulturasi.

3. Masih terlibat pada kegiatan masyarakat yang berkaitan dengan kebudayaan Ngada.

4. Mempunyai waktu yang memadai untuk dimintai informasi.

5. Menghasilkan karya yang berkaitan dengan kebudayaan Ngada.

Penelitian ini dilakukan dalam tiga tahap kegiatan yaitu, tahap satu (1) pengumpulan data dengan metode wawancara dan dokumentasi diikuti dengan tahap dua (2) yakni analisis potensi-potensi kearifan lokal yang berhubungan dengan pendidikan. Potensi-potensi kearifan lokal dalam bidang pendidikan diidentifikasi melalui tahap-tahap berkut ini.

1. Metode wawancara: wawancara dilakukan dengan menggunakan pedoman wawancara yang akan diberikan kepada para nara sumber.

2. Metode dokumentasi: dalam penelitian ini, dokumentasi diperoleh dari hasil penyelidikan yang dimuat dalam bentuk buku tentang kebudayaan Ngada.

Teknik analisis data dalam tahap ini menggunakan langkah-langkah sebagai berikut:

1. Pengumpulan data: dengan menggunakan wawancara dan studi dokumentasi.

2. Reduksi data: merupakan proses merangkum, mengkategorikan, dan membuang data yang dianggap tidak penting yang dipandu oleh tujuan penelitian yang akan dicapai.

3. Display data adalah pendeskripsian sekumpulan informasi tersusun yang memberikan kemungkinan adanya penarikan kesimpulan dan pengambilan tindakan, disajikan dalam bentuk teks naratif, matrik, grafik, diagram, tabel, network dan bagan.

4. Verfikasi dan penegasan kesimpulan: kegiatan interpretasi, yaitu menemukan makna data yang telah disajikan. Data yang telah dianalisis, dijelaksan dan dimaknai dalam bentuk kata-kata untuk mendiskripsikan fakta yang ada dilapangan, pemaknaan atau untuk menjawab pertanyaan penelitian yang kemudian diambil intisarinya.Dalam penelitian ini keabsahan data dilakukan melalui triangulasi dengan sumber, yakni membandingkan hasil wawancara dengan isi dokumen yang berkaitan (Lidi, Dhiki, Ningsih, 2019). 


\section{HASIL DAN PEMBAHASAN}

Penelitian ini telah dilaksanakan dalam dua tahap yakni tahap pertama mengumpulkan data di lapangan dan tahap kedua adalah menganalisis setiap temuan kearifan lokal yang berhubungan dengan bidang pendidikan. Tim peneliti menggali informasi dari nara sumber. Nara sumber dipilih berdasarkan parameter yang telah ditentukan sebelumnya. Berikut adalah nama dari nara sumber-nara sumber tersebut, Bapak Ano Belo, Bapak Antonius Soso, Bapak Thomas Wona, Ibu Helena Bhoke, Bapak Marianus Bao dan Ibu Lina. Kearifan-kearifan lokal yang masih membudaya dan memiliki potensi untuk dikembangkan dalam pendidikan di Kecamatan Golewa Kabupaten Ngada Propinsi Nusa Tenggara Timur adalah sebagai berikut:

1. Paruwitu

Paruwitu adalah salah satu tradisi masyarakat di desa Dolupore, Kecamatan Golewa Kabupaten Ngada. Paruwitu dalam bahasa Indonesia adalah berburu. Tradisi ini dilaksanakan selama 7 hari dan dilakukan dalam bentuk kelompok. Paruwitu dilakukan secara khusus oleh kaum pria, kaum wanita juga mengambil peran kecil dalam kegiatan ini. Dalam satu kelompok, terdiri dari kaum pria dan wanita yang bukan pasangan suami istri/saudara kandung. Beberapa kelompok bekerjasama dalam kegiatan paruwitu ini untuk mendapatkan hasil buruan. Alat yang digunakan selama berburu adalah senjata tajam, kuda dan anjing pelacak. Paruwitu dilakukan di alam bebas, masyarakat wajib membawa peralatan dan bekal saat berburu.

Adapun tahap-tahap dari paruwitu adalah sebagai berikut:

a. Bhe' riwu: pada tahap pertama ini tetua adat memanggil warganya untuk menginformasikan tempat dan waktu untuk kegiatan paruwitu dan juga tentang tata aturan dalam kegiatan paruwitu.

b. Leba manu: Leba manu atau pukul ayam merupakan kegiatan yang dilaksanakan sebelum diadakannya kegiatan berburu. Pada tahap ini, warga desa melakukan kegiatan makan daging ayam bersama sekaligus menyiapkan bekal untuk kegiatan berburu yang akan dilakukan pada esok harinya.

c. Paruwitu: pada tahap ini kelompok berburu memasuki hutan untuk kegiatan berburu.

d. Loka: setelah mendapatkan hasil buruannya, warga membawa hasil buruannya ke tempat peristirahatannya yang disebut Loka. Hewan buruan dibersihkan, dimasak dan dimakan bersama-sama oleh seluruh warga desa.

e. Mori teka lima: Tahap ini merupakan pemberian penghargaan pada orang yang pertama kali membunuh hewan buruan yang disebut mori teka lima. Penghargaan yang diberikan adalah berupa pemberian kepala hewan buruan. Kepala hewan akan diantarkan ke rumah mori teka lima untuk dimanfaatkan oleh seluruh anggota keluarga dalam rumah.

f. Papa modhe: papa modhe dalam bahasa Indonesia berarti saling berbaikan. Pada tahap akhir ini semua warga desa saling memaafkan. Jika ada kesalahpahaman sebelum kegiatan paruwitu atau selama paruwitu berlangsung maka diwajibkan untuk saling memaafkan dan berdamai. 


\section{Permainan Tradisional}

a. Trima

Trima merupakan permainan tradisional dari masyarakat Golewa Kabupaten Ngada. Permainan ini dapat dimainkan baik oleh anak-anak, remaja maupun orang tua. Permainan ini dalam bahasa Indonesianya disebut permainan hadang dan dimainkan di lapangan.

Bahan yang digunakan untuk membuat garis pembatas adalah abu hasil sisa pembakaran kayu. Sebelum bermain, para pemain memilih ketua kelompok. Ketua kelompok yang terpilih memilih anggota kelompoknya dilanjutkan dengan membuat aturan permainan bersama-sama. Lapangan yang berbentuk persegi panjang dibagi menjadi enam kotak dengan membuat garis vertikal dan garis horisontal. Kelompok yang kalah dalam pengundian bertugas menjaga kotak-kotak yang tersedia agar tidak dimasuki oleh kelompok penyerang. Jika berhasil dilewati maka dialah pemenangnya.

b. Adho/Wela Koti

Permainan tradisional Adho/Wela Koti hanya dimainkan oleh kaum pria saja. Adho dimainkan setelah kegiatan paruwitu. Permainan ini dilaksanakan secara berkelompok. Permainan ini hanya terdiri dari dua kelompok dan setiap anggota kelompok harus memiliki ana eda/gasing.

Permainan ini terdiri dari beberapa langkah yakni:

1) Para pemain menetapkan aturan permaian secara bersama

2) Jarak lemparan ditentukan secara bersama sama, biasanya jaraknya 15 meter

3) Tere; .ketua kelompok melakukan pengundian (suit) untuk menentukan kelompok yang pertama kali bermain. Kelompok yang kalah dalam undian (suitan) kalah, menempatkan sepuluh gasingnya dalam barisan yang sama.

4) Foi, syaratnya lima kali bermain, karena ada sepuluh (10) gasing maka ada lima puluh (50) gasing yang harus dijatuhkan. Kelompok pemenang menjatuhkan gasing lawan dalam 5 kali permainan, jika semuanya berhasil maka masuk ke tahap selanjutnya

5) Besu, adu putar, menjatuhkan hanya salah satu 10 gasing lawan maka lanjut ke tahap berikutnya.

6) Peo adalah permainan puncak, gasing ditempatkan pada suatu area kemudian diputar, gasing pemain dilemparkan ke gasing dibagian dalam, jika gasing pemain dapat melempar keluar gasing utama keluar dari arena maka menang. Syarat menang adalah mampu melempar keluar gasing utama dalam arena dan gasing tersebut berhenti berputar, dan gasing pemain jangan berhenti berputar, jika tetap berputar maka kita juga kalah walaupun gasing kita berhasil melempar keluar gasing utama.

3. Ritual Kosubue/Ruki Kosubue

Ritual ini bertujuan untuk menguji kejujuran para gadis yang beranjak ke masa remaja tentang kesucian. Ritual ini terdiri dari beberapa tahap yakni:

a. Sekelompok gadis diasingkan ke rumah perasingan dan terputus dengan dunia luar. Makanan akan dibawakan oleh orang yang dipercaya ke rumah pengasingan mereka.

b. Ritual seseado; pada ritual ini beras dimasukkan ke dalam bere (tas anyaman dari daun lontar/daun pandan) dan bere dilapisi dengan daun waru kemudian bere ditutup. Keesokan harinya diamati jika daun waru sobek maka sebagai pertanda ada gadis yang tidak suci lagi, maka para gadis diminta untuk jujur atau ada pun petanda lainnya 
yaitu sebanyak apapun beras dimasukan ke dalam bere tetap tidak dapat memenuhi ruang di wadah yang digunakan.

c. Sanksi bagi pelanggaran: denda kerbau pada pria yang telah menodai kesucian gadis tersebut, sanksi masyarakat lainnya gadis tersebut tidak akan ditaksir oleh pemuda dalam kampung tersebut. Pelanggaran dianggap merusak nama baik kampung dan kesehatan manusia itu sendiri.

Tradisi berburu (Paruwitu) masyarakat setempat selanjutnya dikembangkan untuk menjadi model pembelajaran sains. Model yang dikembangkan tidak terlepas dari teoriteori belajar yang menjadi dasar teori dan mendukung pengembangan model.

Pengembangan model pembelajaran sains dari Paruwitu telah diteliti oleh Lidi, dkk pada tahun 2018. Adopsi paruwitu untuk model pembelajaran yakni: kekhasan dan langkah-langkah paruwitu diadopsi menjadi langkah-langkah pembelajaran dengan karakteristik yang sesuai dari kekhasan dari paruwitu. Dalam model pembelajaran ini, peserta didik diajak untuk secara mandiri mengamati dan mempelajari lingkungan sekitar. Lingkungan sekitar anak adalah sumber belajarnya, anak mengkontruksi pengetahuannya secara mandiri dalam kelompok belajarnya dengan bimbingan guru. Sebelum turun ke alam bebas/lingkungan sekitarnya, anak wajib dibekali dengan pengetahuan dasar, arahan dan bimbingan awal guru serta media pembelajaran seperti lembar kegiatan siswa yang menjadi panduan/arahan siswa dalam bekerja. Sintaks dari model pembelajaran ini adalah Bhe' riwu, Leba manu, Paruwitu, Loka, mori teka lima, Papa modhe. Hasil penelitian menunjukkan bahwa model pembelajaran paruwitu teruji dapat meningkatkan hasil belajar dan minat siswa dalam pembelajaran sains (Lidi, dkk, 2019).

Permainan Trima dan Adho/Wela Koti dapat diadopsi dalam pembelajaran di kelas agar dapat meningkatkan aktifitas siswa dan membuat suasana kelas menjadi lebih hidup. Permainan merupakan aktivitas utama anak-anak dan dianggap wajib untuk mendapatkan teman, sarana, rekreasi dan untuk olahraga (Yudiwinata dan Handoyo. 2014). Secara lebih khusus Nur (2013) menyatakan bahwa permainan tradisional memberikan dampak positif untuk mengembangkan keterampilan emosi dan sosial anak. Didukung oleh Azizah (2016), melalui permainan tradisional anak memperoleh kegembiraan., keterampilan dan kecekatan kaki dan tangannya menggunakan kekuatan tubuhnya, ketajaman penglihatannya, kecerdasan pikirannya, keluwesan gerak tubuhnya, menirukan alam lingkungannya, memudahkan gerak irama, lagu dan kata-kata yang sesuai dengan arti dan gerakannya. Lebih lanjut hasil temuannya menunjukkan bahwa penerapan permainan tradisional dalam pembelajaran lebih efektif dalam meningkatkan motivasi belajar siswa. Di sisi lain, berdasarkan hasil temuan Nataliya (2015), permainan tradisional juga berpengaruh dalam meningkatkan kemampuan berhitung pada siswa sekolah dasar. Oleh karena itu perlu kiranya disusun sebuah model bimbingan yang berbasis pada permainan.

Bermain adalah suatu aktifitas yang langsung dan spontan dilakukan seorang anak bersama orang lain atau dengan menggunakan benda-benda sekitarnya dengan senang, sukarela dan imajinatif serta dengan menggunakan perasaannya, tangannya atau seluruh anggota tubuhnya. Melalui permainan-permainan siswa bisa mengembangkan nalar, komunikasi serta pemecahan masalah yang dituntut dalam kurikulum tingkat satuan pendidikan (Muslimin, Putri, dan Somakim, 2012). Karakter anak pun dapat dibangun 
melalui permainan tradisional seperti nilai-nilai kebersamaan, kejujuran, tanggung jawab, sikap lapang dada (kalau kalah), dorongan berprestasi, dan taat pada aturan (Nur, 2013), sehingga pendidikan menjadi bermakna dalam arti setiap peserta didik dapat memperoleh iptek, keterampilan, dan nilai-nilai kemanusiaan sebagai bekal mereka memasuki persaingan di dunia global.

Nilai-nilai karakter dalam ritual Kosubue/Ruki Kosubue seperti kejujuran, kepatuhan, tanggungjawab, rasa hormat, dapat dipercaya, dan saling menghargai dapat diambil dan diterapkan dalam pendidikan karakter. Peningkatan kualitas sumber daya manusia dapat ditempuh melalui perbaikan sistem pendidikan yang mengarah pada pembentukan karakter siswa sejak tingkat pra sekolah sampai perguruan tinggi. Hal ini senada dengan pernyataan Zulnuraini (2012), yakni muatan nilai-nilai karakter yang terdapat dalam pembelajaran pada saat melakukan kegiatan pembelajaran meliputi; nilai disiplin (discipline), rasa hormat dan perhatian (respect), tekun (diligence), tanggung jawab (responsibility), dapat dipercaya (trustworthiness), berani (courage), ketulusan (honesty), integritas (integrity), peduli (caring), jujur (fairness), kewarganegaraan (citizenship), dan ketelitian (carefulness).

Pemerintah telah mencanangkan kurikulum yang penekanannya lebih banyak pada pendidikan karakter. Pendidikan karakter menjadi salah satu program prioritas dalam Kebijakan Nasional Pembangunan Karakter Bangsa. yang dilaksanakan dalam beberapa tahap. Tahap pertama dan prioritas pada 2010-2014, merupakan fase konsolidasi dan implementasi, tahap kedua dan prioritas 2015-2019, merupakan fase pemantapan strategi dan implementasi, serta tahap ketiga dan prioritas 2020-2025 merupakan fase pengembangan berkelanjutan dari hasil yang telah dicapai pada tahap I dan II (Maduriana dan Seniwati, 2015; Alawiyah, 2012). Pendidikan karakter menjadi wadah dalam menghimpun nilai-nilai keluhuran umat manusia yang terhimpun dari agama, budaya, adat istiadat, kearifan lokal dan sebagainya. Heraclitus (dalam Lickona, 2012, 12) mengatakan bahwa "Karakter adalah takdir, karakter akan membentuk takdir seseorang".

\section{PENUTUP}

Berdasarkan hasil penelitian yang telah dilakukan, peneliti dapat menyimpulkan beberapa hal sebagai berikut: hasil identifikasi potensi kearifan lokal pada masyarakat Ngada yang berpotensi untuk dikembangkan dalam pendidikan antara lain Paruwitu, Trima, Adho/Wela Koti, dan Kosubue/Ruki Kosubue. Dari beberapa kearifan lokal yang ada ini, guru perlu jeli melihat dan mengintegrasikannya dalam proses pembelajaran agar siswa bukan saja memiliki pengetahuan semata tapi siswa juga mampu mengenal budayanya secara baik agar secara tidak langsung guru dan siswa dapat mempertahankan budaya serta nilai-nilai kearifan lokal yang ada.

\section{UCAPAN TERIMAKASIH}

Ucapan terima kasih disampaikan kepada Pemerintah Kabupaten Ngada terlebih khusus kepada Camat Golewa beserta jajarannya dan juga kepada para narasumber yang telah membantu dan mendukung kegiatan penelitian yang telah dilaksanakan di Kabupaten Ngada. Tidak lupa penulis ucapkan terimakasih kepada sejawat dan berbagai pihak yang 
telah memberikan masukan berharga lewat diskusi yang dapat menambah wawasan. Harapannya, tulisan sederhana ini bermanfaat bagi dunia pendidikan.

\section{DAFTAR PUSTAKA}

Alawiyah, F. (2012). Kebijakan dan Pengembangan Pembangunan Karakter Melalui Pendidikan di Indonesia. Jurnal Aspirasi, 3 (1), 87-101. doi: 10.22212/aspirasi.v3i1.259

Azizah, I. M. (2016). Efektivitas Pembelajaran Menggunakan Permainan Tradisional Terhadap Motivasi dan Hasil Belajar Materi Gaya Di Kelas Iv Min Ngronggot Nganjuk. Dinamika Penelitian, 16 (2), 279-308. doi: 10.21274/dinamika.2016.16.2.

Diana, N. (2012). Manajemen Pendidikan Berbasis Budaya Lokal Lampung (Analisis Eksploratif Mencari Basis Filosofis). Jurnal Analisis, XII (1), 183-208. doi: 10.24042/ajsk.v12i1.636

Laksana, D.N.L \& Widiastika, I. G. (2017). Pengembangan Multimedia Pembelajaran Tematik Sekolah Dasar Berbasis Budaya Lokal Masyarakat Flores. Jurnal Pendidikan Dasar Nusantara, 2 (2), 151-162. Retrieved from https://ojs.unpkediri.ac.id/index.php/pgsd/article/view/549

Lickona, T. (2012). Character Matters. Jakarta: PT Bumi Aksara.

Lidi, M.W., Dhiki, Y.Y dan Ningsih. (2018, 20 October). The Development Of Science Learning Model Based On Local Wisdom Of Ngada Society At Elementary School Combined By Audio Visual Media. Paper presented at the $1^{\text {st }}$ International Conference on Science and Technology for an Internet of Things, Universitas Sarjanawiyata Taman Siswa Yogyakarta, Indonesia. Publisher EAI 2019. doi: 10.4108/eai.19-10-2018.2282159

Maduriana, I. M., \& Seniwati, N. P. (2015). Pengembangan Bahan Ajar IPA SD Bermuatan Pendidikan Karakter Berbasis Tradisi Lisan Bali. Jurnal Kajian Bali, 5 (2), 369-390. Retrieved from https://ojs.unud.ac.id/index.php/kajianbali/article/view/16781

Muslimin, Putri, R. I. I \& Somakim. (2012). Desain Pembelajaran Pengurangan Bilangan Bulat Melalui Permainan Tradisional Congklak Berbasis Pendidikan Matematika Realistik Indonesia di Kelas IV Sekolah Dasar. Jurnal Kreano, 3 (2), 100-112. doi: 10.15294/kreano.v3i2.2642

Nataliya, P. (2015). Efektivitas Penggunaan Media Pembelajaran Permainan Tradisional Congklak Untuk Meningkatkan Kemampuan Berhitung Pada Siswa Sekolah Dasar. Jurnal Ilmiah Psikologi Terapan, 3 (2), 343- 358. doi: 10.22219/jipt.v3i2.3536

Normina. (2017). Pendidikan dalam Kebudayaan. Ittihad Jurnal Kopertis Wilayah XI Kalimantan, 15(28), 17-28. Retrieved from https://ojs.uin-antasari.ac.id

Nur, H. (2013). Membangun Karakter Anak Melalui Permainan Tradisional. Jurnal Pendidikan Karakter, 3 (1), 87-94. doi: 10.21831/jpk.v0i1.1290

Sebo, L., Adayani, \& Subiyantoro, S. (2017). Nilai Pendidikan Karakter dan Kearifan Lokal Legenda Wae Reke Masyarakat Ngada, Nusa Tenggara Timur Dalam Relevansinya dengan Pembelajaran Sastra Tingkat SLTP. Jurnal Aksara, 2 (1), 3245. Retrieved from https://www.semanticscholar.org 
UUD 1945 PASAL 28C ayat 1 dan 2, Hak Asasi Manusia.

UUD 1945 pasal 31 ayat 1 dan 2, Hak dan Kewajiban Warga Negara

Yudiwinata, H.P \& Handoyo, P. (2014). Permainan Tradisional Dalam Budaya dan Perkembangan Anak. Paradigma, 2 (3), 1-5. Retrieved from https://ojs.jurnalmahasiswa.unesa.ac.id

Zafi, A. A. (2017). Transformasi Budaya Melalui Lembaga Pendidikan (Pembudayaan dalam Pembentukan Karakter). Sosiohumaniora, 3 (2), 105-112. doi: 10.30738/sosio.v3i2.937

Zulnuraini. (2012). Pendidikan Budi pekerti: Konsep, Implementasi dan Pengembangannya di Sekolah Dasar di Kota Palu. Jurnal DIKDAS, 1 (1),-. Retrieved from https://adoc.tips 